\title{
Article \\ Effect of Mixing Light-Burned MgO with Different Activity on the Expansion of Cement Paste
}

\author{
Yang Wang ${ }^{1}$, Caoning Zhang ${ }^{2}$ and Lingling $\mathrm{Xu}{ }^{1, *}$ \\ 1 College of Materials Science and Engineering, Nanjing Tech University, Nanjing 210009, China; \\ 18362080050@163.com \\ 2 Hangzhou Silan Integrated Circuits Co., Ltd., Hangzhou 310023, China; 18013006534@163.com \\ * Correspondence: xulingling1964@163.com; Tel.: +86-13951846173
}

Citation: Wang, Y.; Zhang, C.; Xu, L. Effect of Mixing Light-Burned $\mathrm{MgO}$ with Different Activity on the Expansion of Cement Paste. Crystals 2021, 11, 1360. https://doi.org/ $10.3390 /$ cryst11111360

Academic Editor: Chongchong Qi

Received: 7 October 2021

Accepted: 28 October 2021

Published: 8 November 2021

Publisher's Note: MDPI stays neutral with regard to jurisdictional claims in published maps and institutional affiliations.

Copyright: (c) 2021 by the authors. Licensee MDPI, Basel, Switzerland. This article is an open access article distributed under the terms and conditions of the Creative Commons Attribution (CC BY) license (https:// creativecommons.org/licenses/by/ $4.0 /)$.

\begin{abstract}
In mass concrete, shrinkage resulting from temperature drop and drying leads to cracking, which can seriously affect the strength and durability of cement-based materials. Fortunately, expansion agents can deter or prevent these effects, especially $\mathrm{MgO}$ expansion agents (MEAs). In this study, the effects of four MEAs of different activity on the expansion properties, strength, and hydration of cement paste were explored. The different expansion phenomena between the high activity and low activity $\mathrm{MgO}$ was especially explained by the hydration model and dynamic theory. The results indicate that when the other conditions were the same, higher curing temperature and dosage could improve the expansion to some extent. Moreover, the hydration of high activity $\mathrm{MgO}$ and the expansion behavior occurred mainly in the early hydration stage, while the hydration of low activity $\mathrm{MgO}$ and the expansion behavior had a high contribution rate in the later stage, and the final expansion of cement mixed with low activity $\mathrm{MgO}$ was larger.
\end{abstract}

Keywords: $\mathrm{MgO}$ expansion agent; expansion properties; hydration model

\section{Introduction}

In the nineteenth and early twentieth centuries, a lot of structural damage to bridges and dams took place not long after being put in service due to the high content of $\mathrm{MgO}$ contained in cement used in Europe [1,2]. Since then, much more research has been undertaken to investigate the soundness of dead-burned $\mathrm{MgO}$ in cement. Additionally, standards for limiting the content of $\mathrm{MgO}$ in cement have been established in many countries. For example, the content of $\mathrm{MgO}$ should be below $5 \%$ in cement and can be $6 \%$ when passing soundness testing under autoclaving according to Chinese standards [3].

It has been found that the expansion produced by $\mathrm{MgO}$ could be utilized to compensate for the shrinkage of cementitious material under certain conditions. Mehta [4] proposed in 1980 that when $5 \%$ of the periclase calcined at $900 \sim 950{ }^{\circ} \mathrm{C}$ was added to the concrete, the expansion stress generated during the hydration process could compensate for the shrinkage and cracks of the concrete. Since then, many more efforts [5-8] have been put into controlling cracks in concrete by taking advantage of the delayed expansion of $\mathrm{MgO}$. Meanwhile, some new problems should be solved, the most significant of which is the relatively little available source of the high $\mathrm{MgO}$ cement. Hence, in order to solve the limitation of receiving source and to better control the quality of $\mathrm{MgO}$, magnesite was separately calcined to be an $\mathrm{MgO}$ expansion agent. In addition, dolomite, serpentine, and other magnesium-containing minerals were also considered to prepare $\mathrm{MgO}$ expansion agent [9-15].

Some work has been performed on the hydration mechanism of periclase in water. $\mathrm{P}$ Liu $[16,17]$ believed that firstly, $\mathrm{H}_{2} \mathrm{O}$ molecules chemically adsorb on the surface of $\mathrm{MgO}$ defects in water, and then the surface of $\mathrm{MgO}$ produces hydroxylation. Mejias J A [18] thought that this hydroxylation reaction rearranges the atoms at the interface between $\mathrm{MgO}$ and $\mathrm{H}_{2} \mathrm{O}$. Then, a layer of $\mathrm{Mg}(\mathrm{OH})_{2}$ directly forms on the surface; or the dissociated 
$\mathrm{Mg}^{2+}$ intermediate forms a supersaturated solution with $\mathrm{OH}^{-}$, finally crystallizing to $\mathrm{Mg}(\mathrm{OH})_{2}$. However, Wogelius [19] considered that hydroxylation takes place in the nearsurface region of $\mathrm{MgO}$ crystals. In water systems, the surface of $\mathrm{MgO}$ reacts with $\mathrm{H}^{+}$to form a surface layer similar to brucite structure. Then, $\mathrm{Mg}^{2+}$ are replaced by $\mathrm{H}^{+}$to form dissociated $\mathrm{Mg}^{2+}$ intermediate, finally spreading to the surface and forming $\mathrm{Mg}(\mathrm{OH})_{2}$ crystal. Meanwhile Fengze Cao [20] found that the shape of $\mathrm{Mg}(\mathrm{OH})_{2}$ crystal depends on the reactivity of $\mathrm{MgO}$. Low reactivity of $\mathrm{MgO}$ leads to a formation of an octahedron, while high reactivity of $\mathrm{MgO}$ leads to a formation of a hexagonal prism.

Numerous studies have shown that the hydration degree of periclase is affected by many factors. Hongwu Zheng [21] considered that the factors affecting the degree of hydration of periclase includes the number of $\mathrm{MgO}$ crystals, the size of the $\mathrm{MgO}$ crystal, and the curing environment of cement paste. The hydration kinetics and hydration degree should be determined with certain conditions, such as the number, size, and defects of $\mathrm{MgO}$ crystal. Haiyan Qian [22] studied the relationship between hydration degree and time of light-burned $\mathrm{MgO}$ at different temperatures. She found that the hydration reaction of light-burned $\mathrm{MgO}$ is consistent with the first-order reaction kinetics; that is, the hydration process is controlled by chemical reactions. Jiaping Liu [23] and Changwen Miao [24] found that the effect of increasing temperature on hydration of high activity magnesium oxide expansion agent is more significant. The expansion of high activity magnesium oxide expansion agent at normal temperature is lower than that of low activity magnesium oxide expansion agent, but higher than that of the low activity magnesium oxide expansion agent at high temperature. Therefore, Lanqing Yu [25] considered that MEAs with a low hydration reactivity ranked better in cracking resistance than MEAs with a high hydration reactivity when the light-burned MEA is applied to field concrete poured at a high temperature.

It is well known that the reaction of periclase with water produces magnesium hydroxide $\left(\mathrm{Mg}(\mathrm{OH})_{2}\right)$ with a volume expansion of about $148 \%$ [26,27], resulting in uneven deformation of the paste, eventually causing poor soundness of cement. However, the increase of the volume of hydration product is not exactly equal to the macroscopic expansion produced by $\mathrm{MgO}$ in cement paste. There were many explanations for the hydration mechanism of periclase, and most experts agreed with the theory of the swelling of absorbing water proposed by Deng Min [3] and the theory of crystal growth pressure proposed by Chatterji [28]. Based on these, combined with the hydration mechanism of $\mathrm{MgO}$ single crystals [28] and polycrystals [29] (Figure 1), Liwu Mo [3] proposed the hydration model of two types of $\mathrm{MgO}$ expansion agent in cement paste, including porous MEAs with high activity and less porous MEAs with low activity. He believed that there were three reasons for the different expansions of the two expansion agents. First, the activity of the hydration reaction was different, the second was the internal structure of the MEA, and the third was the difference in the matrix performance of the cement hydration product [3]. Fengze Cao's research $[30,31]$ on the hydration process of MEAs in mortar showed that the expansion is driven by the recrystallization of $\mathrm{Mg}(\mathrm{OH})_{2}$. The sufficient water supply facilitates the immigration of $\mathrm{Mg}^{2+}$ and the recrystallization of $\mathrm{Mg}(\mathrm{OH})_{2}$, which generates a high crystal growth pressure and promotes the expansion of mortars.

Light-burned $\mathrm{MgO}$ expansion agent can effectively compensate the shrinkage of cement-based materials, ensure the quality of the project, and have broad prospects for development because of the good expansion properties of periclase in the hydration stage. Due to the complex engineering conditions, the activity and dosage of light-burned $\mathrm{MgO}$ expansion agent will change accordingly to achieve the best effect. In this study, the relationship between various conditions and hydration expansion was discussed, with the aim of serving as a guide for the application of $\mathrm{MgO}$ expansion agents. 


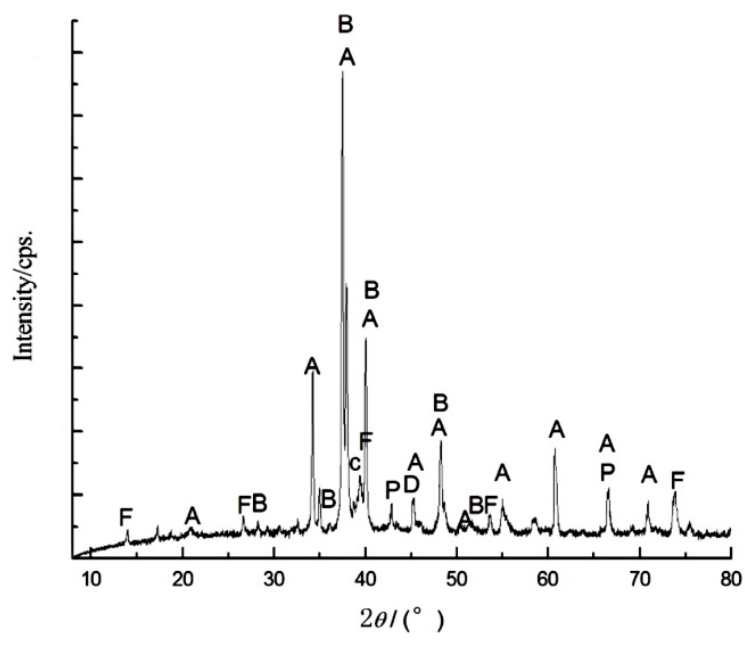

Figure 1. The XRD pattern of $\mathrm{DM}^{\#}\left(\mathrm{~A}-\mathrm{C}_{3} \mathrm{~S}, \mathrm{~B}-\mathrm{C}_{2} \mathrm{~S}, \mathrm{C}-\mathrm{C}_{3} \mathrm{~A}, \mathrm{~F}-\mathrm{C}_{4} \mathrm{AF}, \mathrm{D}-\mathrm{CaO}, \mathrm{P}-\mathrm{MgO}\right)$.

\section{Materials and Methods}

\subsection{Materials}

Clinker with low magnesium content $\left(\mathrm{DM}^{\#}{ }^{\#}\right)(45 \sim 80 \mu \mathrm{m}$ particle size) produced by Jiangnan Onoda Cement Co., Ltd (Nanjing, China) was used in this experiment. The chemical composition, the mineral composition, and the X-ray diffraction (XRD) pattern of DM1 $^{\#}$ are presented in Tables 1 and 2, and Figure 1, respectively. Gypsum was mixed into the cement system at a concentration of $5 \%$ weight of cement to adjust the cementation time of cement clinker, and the whole system was called $\mathrm{C1}^{\#}$.

Table 1. The chemical composition of cement clinker (wt/\%).

\begin{tabular}{ccccccccccc}
\hline Material & Loss & $\mathrm{SiO}_{2}$ & $\mathrm{Fe}_{2} \mathrm{O}_{3}$ & $\mathrm{Al}_{2} \mathrm{O}_{3}$ & $\mathrm{SO}_{3}$ & $\mathrm{CaO}$ & $\mathbf{K}_{2} \mathrm{O}$ & $\mathrm{Na}_{2} \mathbf{O}$ & $\mathbf{M g O}$ & Total \\
\hline DM1 $^{\#}$ & 1.16 & 20.51 & 4.47 & 3.89 & 0.38 & 65.53 & 0.54 & 0.23 & 1.81 & 98.52 \\
\hline
\end{tabular}

Table 2. The mineral composition of cement clinker (wt/\%).

\begin{tabular}{cccccccc}
\hline Material & $\mathbf{C}_{3} \mathbf{S}$ & $\mathbf{C}_{2} \mathbf{S}$ & $\mathbf{C}_{4} \mathbf{A F}$ & $\mathbf{C}_{3} \mathbf{A}$ & $\mathbf{f}-\mathrm{CaO}$ & $\mathbf{f}-\mathbf{M g O}$ & Total \\
\hline DM1 $^{\#}$ & 60.00 & 22.18 & 13.19 & 3.38 & 0.56 & 1.25 & 100.46 \\
\hline
\end{tabular}

Herein, four types of light-burned MgO manufactured in Jiangsu Bote New Materials CO., Ltd. (Nanjing, China) were used in the experiments. Hydration activity that was obtained from the citric acid method and other basic physical properties of these samples are summarized in Table 3, and its chemical composition are shown in Table 4. The XRD patterns of light-burned $\mathrm{MgO}$ are shown in Figure 2.

Table 3. The basic properties of four $\mathrm{MgO}$.

\begin{tabular}{cccc}
\hline Samples & $\begin{array}{c}\text { Active Reaction } \\
\text { Time (s) }\end{array}$ & Density $\left(\mathbf{k g} / \mathbf{m}^{\mathbf{3}}\right)$ & $\begin{array}{c}\text { Specific Surface } \\
\text { Area }\left(\mathbf{m}^{\mathbf{2}} \mathbf{g}\right)\end{array}$ \\
\hline $\mathrm{A}_{1}$ & 65 & 3790 & 17.99 \\
$\mathrm{~A}_{2}$ & 110 & 3500 & 12.25 \\
$\mathrm{~A}_{3}$ & 143 & 3430 & 13.13 \\
$\mathrm{~A}_{4}$ & 190 & 3730 & 11.69 \\
\hline
\end{tabular}


Table 4. The chemical composition of four $\mathrm{MgO}$ (wt/\%).

\begin{tabular}{ccccccccccc}
\hline Material & $\mathrm{SiO}_{2}$ & $\mathrm{Fe}_{2} \mathrm{O}_{3}$ & $\mathrm{Al}_{2} \mathbf{O}_{3}$ & $\mathrm{CaO}$ & $\mathbf{M g O}$ & $\mathrm{K}_{\mathbf{2}} \mathrm{O}$ & $\mathrm{Na}_{2} \mathrm{O}$ & $\mathrm{SO}_{3}$ & Loss & Total \\
\hline $\mathrm{A}_{1}$ & 2.76 & 0.26 & 0.42 & 3.18 & 88.52 & 0.03 & 0.06 & 0.61 & 3.62 & 99.46 \\
$\mathrm{~A}_{2}$ & 2.46 & 0.29 & 0.43 & 3.15 & 90.02 & 0.02 & 0.05 & 0.68 & 2.54 & 99.64 \\
$\mathrm{~A}_{3}$ & 4.28 & 0.32 & 0.45 & 3.22 & 87.82 & 0.02 & 0.05 & 0.18 & 2.16 & 99.1 \\
$\mathrm{~A}_{4}$ & 3.98 & 0.3 & 0.4 & 3.01 & 89.32 & 0.01 & 0.04 & 0.63 & 2.04 & 99.73 \\
\hline
\end{tabular}

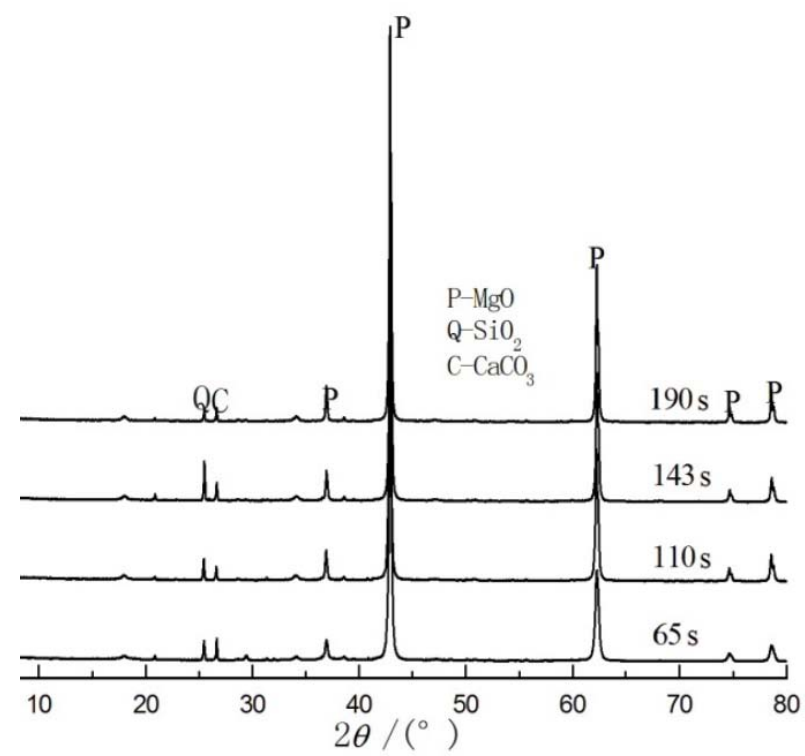

Figure 2. The XRD patterns of four light-burned $\mathrm{MgO}$.

\subsection{Sample Preparation}

$\mathrm{C}^{\#}$ cement slurry samples were prepared in strict accordance with GB/T 1346-2011 (in China). Then, these materials, including $\mathrm{C}^{\#}$ cement and four different types of lightburned $\mathrm{MgO}$, were respectively blended well. After being mixed well, cement slurry samples were put in $20 \mathrm{~mm} \times 20 \mathrm{~mm} \times 20 \mathrm{~mm}$ cubes for compressive strength test. For measuring the expansion degree of the cement specimens, the specimens were cast into metallic molds, which could separate the cement paste into $20 \mathrm{~mm} \times 20 \mathrm{~mm} \times 80 \mathrm{~mm}$ cuboid specimens. After being solidified (approximately $24 \mathrm{~h}$ ), the cement specimen cubes were stripped and maintained for 1, 3, 7, 14, 28, 60, 90 days respectively at different temperature in water.

\subsection{Methods}

\subsubsection{Expansion Rate Test}

The initial length of the solidified $\left(\mathrm{L}_{0}\right)$ specimens mixed with different kinds and different mixing amounts of light-burned $\mathrm{MgO}$ should be measured immediately. Next, the specimens were cured at different temperature in water until the specified ages for measuring the length of different ages $\left(\mathrm{L}_{1}\right)$. The expansions of specimens may be determined as follows:

$$
\text { Expansion }(\%)=\left(\mathrm{L}_{1}-\mathrm{L}_{0}\right) \times 100 \% / \mathrm{L}_{0}
$$

\subsubsection{Compressive Strength Test}

Cement strength was determined in accordance with the plastic mortar strength test (Chinese Standard GB17671, or ISO 679). Through the curing of the specified period, three samples were selected for each condition and then investigated for compressive strength. Finally, the average value was obtained as the compressive strength of the cement specimens. 


\subsubsection{Scanning Electron Microscopy (SEM) Characterization}

Scanning electron microscopy (SEM) was applied to observe the hydration morphology of these specimens at different ages at $20^{\circ} \mathrm{C}$.

\subsubsection{Measurement of Hydration Degree of Periclase in Cement Paste}

A quantitative X-ray diffractometric method (XRD internal standard method) using $\mathrm{ZnO}$ as an internal standard substance and high-purity $\mathrm{MgO}, \mathrm{Mg}(\mathrm{OH})_{2}$ as admixture has been conducted for determining the content of periclase in above-mentioned cement paste specimens. The measurement data were obtained within the $35 \sim 45^{\circ}$ range for the specimens at a speed of $0.25^{\circ} / \mathrm{min}$ with $\mathrm{Cu} \mathrm{K} \alpha$ radiation. According to the content of periclase in different hydration ages, the corresponding relationship among the hydration degree of periclase in the cement paste, the curing temperature and the curing time was determined.

\section{Results and Discussion}

\subsection{Expansion Property of Specimens}

3.1.1. The Effects of Added MgO Content on the Expansion of Cement Pastes Mixed with Light-Burned $\mathrm{MgO}$

Figure 3 shows the expansion curves of cement pastes containing different hydration activities and different contents of $\mathrm{MgO}$ cured at $20^{\circ} \mathrm{C}$ in water. It was obvious that any specimens without active $\mathrm{MgO}$ expand slightly (about only $0.037 \%$ ) in the first 7 days, but after 7 days the expansion curve levels off or even falls-namely, cement specimens no longer expand or even begin to shrink. This phenomenon may result from partial irreversible stress expansion caused by the early production (AFt). The mixing of $\mathrm{MgO}$ resulted in continuous expansion on cement clinker after 7 days. Additionally, the expansion of cement pastes clearly increased with added content of $\mathrm{MgO}$ in cement.

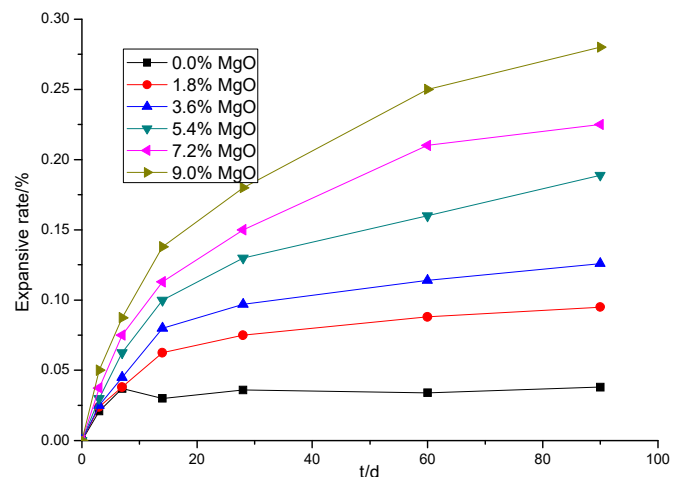

(a)

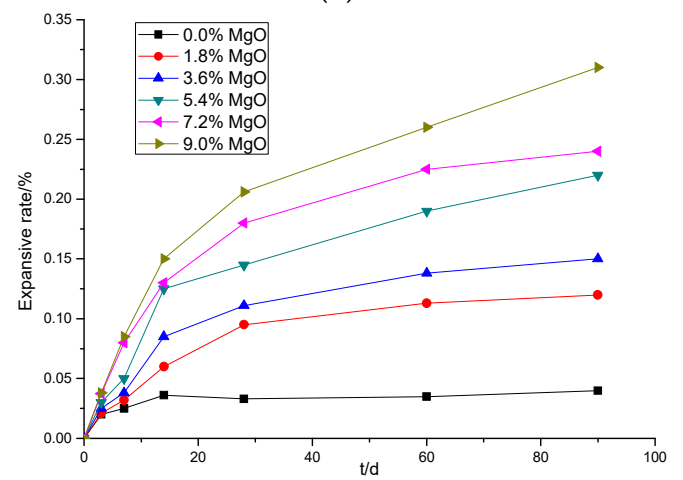

(c)

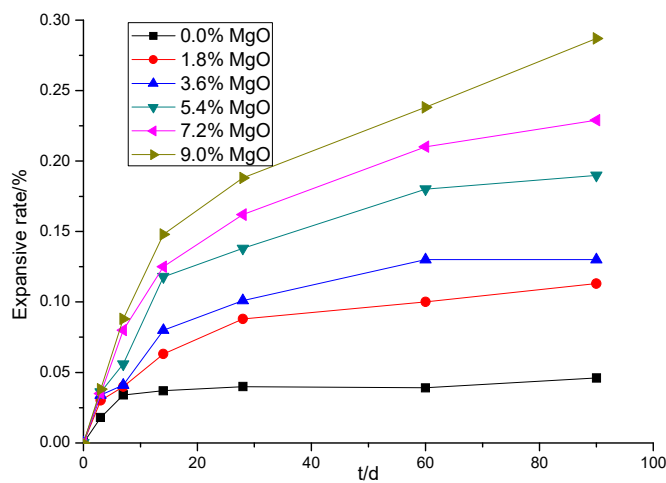

(b)

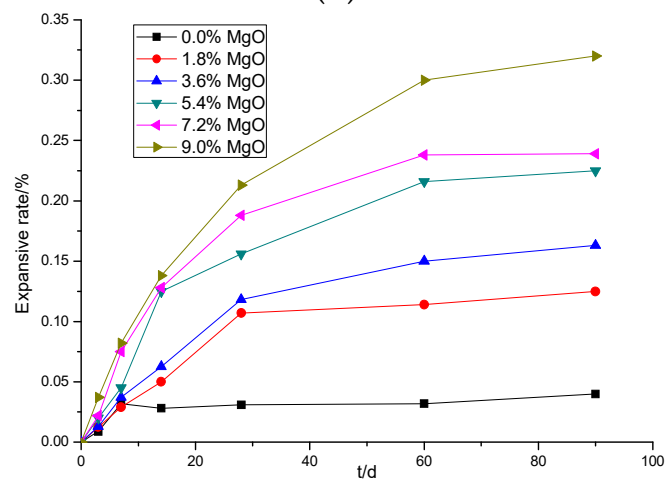

(d)

Figure 3. The expansion curves of cement paste mixed with $\mathrm{MgO}$ of different activities and amounts at $20^{\circ} \mathrm{C}$ curing: (a) M65 s; (b) M110 s; (c) M143 s; (d) M190 s. 
It was apparent that the content of $\mathrm{MgO}$ did not have a linear relationship with its corresponding expansion rate. The reason may be that specimens were in the plastic expansion stage before cement paste reached full hardening. In this stage, the platy brucite produced by the hydration of $\mathrm{MgO}$ interspersed in gel pores generated by cement hardening, resulting in the condition that the enlarged volume from the hydration of $\mathrm{MgO}$ did not fully contribute to the expansion value of cement [28], ultimately leading to nonlinear relationship between the content of $\mathrm{MgO}$ and its corresponding expansion rate.

In summary, within a certain range, the greater the $\mathrm{MgO}$ content, the greater and faster the expansion rate. In addition, the $\mathrm{MgO}$ content did not have a linear relationship with its corresponding expansion rate.

3.1.2. The Effects of Temperature on the Expansion of Cement Paste Mixed with Light-Burned $\mathrm{MgO}$

For observing more obvious expansion phenomena, $10 \% \mathrm{MgO}$ of different activities was mixed in the cement pastes. The expansion curves of samples mixed $10 \%$ different activity $\mathrm{MgO}$ at different temperature were presented in Figure 4. As shown in Figure 4, it caused some obvious expansions as the curing temperature increases. At the temperature of $20^{\circ} \mathrm{C}, 30^{\circ} \mathrm{C}$ and $38^{\circ} \mathrm{C}$, these expansion curves continued to increase slowly, namely, the expansion rate grew gradually with the growth of time. Furthermore, it continued to grow after 90 days. When the curing temperature is $60^{\circ} \mathrm{C}$, the expansion of specimens is greatly accelerated, especially for the specimens mixed with $\mathrm{MgO}$ (110 s), $\mathrm{MgO}$ (143 s) and $\mathrm{MgO}$ (190 s), and these corresponding curves all rise slowly or even level off after 14 days. On the condition that the curing temperature is $80^{\circ} \mathrm{C}$, the expansion curve sharply increases before 14 days, while it tends to flatten without growth after 14 days. That is to say, specimens almost reach the "ultimate" expansion through 14 days of maintenance.

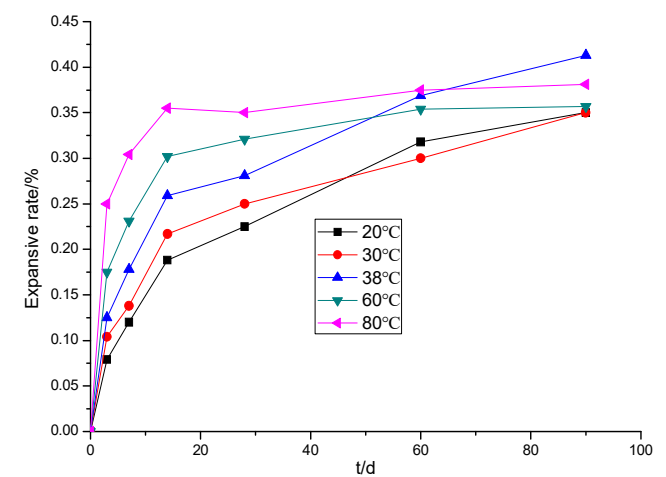

(a)

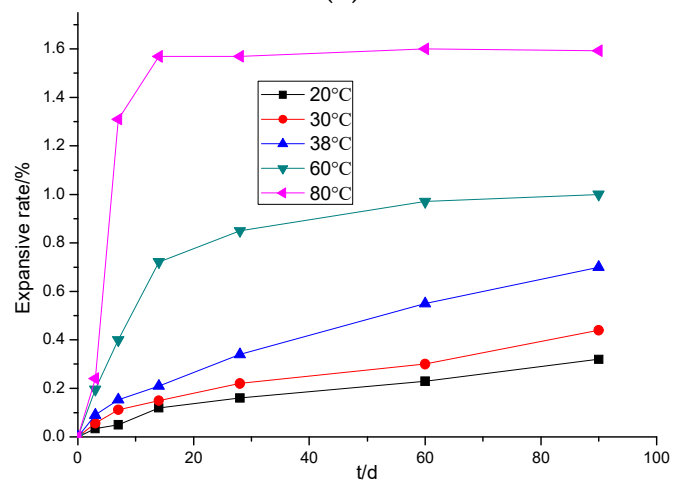

(c)

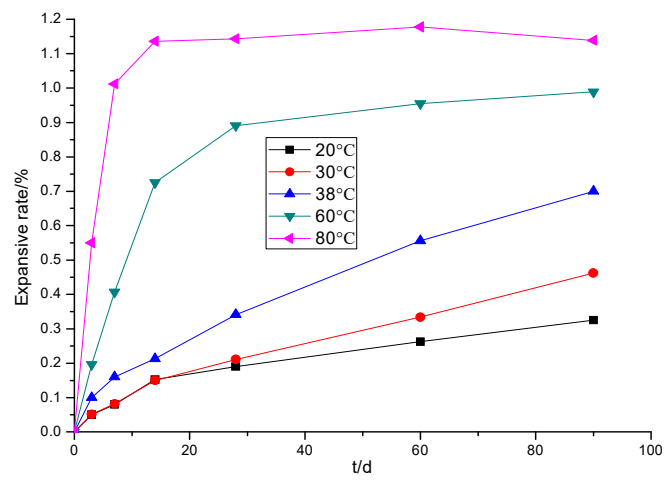

(b)

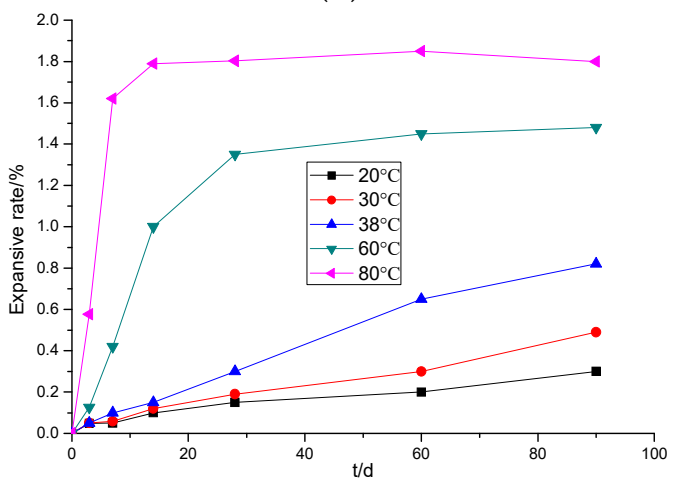

(d)

Figure 4. The expansion curves of cement paste mixed with $\mathrm{MgO}$ of different activities at different temperatures: (a) M65 s; (b) M110 s; (c) M143 s; (d) M190 s. 
The above reflect that the higher the curing temperature is, the faster the expansion of cement mixed with light-burned $\mathrm{MgO}$ is, and the shorter time reaching stable expansion is.

\subsubsection{The Effects of $\mathrm{MgO}$ Activity on the Expansion of Cement Paste Mixed with Light-Burned $\mathrm{MgO}$}

It can be observed in Figure $5 \mathrm{a}, \mathrm{b}$ that different hydration activities of $\mathrm{MgO}(9 \%)$ have some influences on cement paste. Evidently, the specimens mixed with $\mathrm{MgO}$ (65 s) expand rapidly in the early stages at these temperatures, such as an expansion value of $0.079 \%$ after 3 days, $0.120 \%$ after 7 days, and $0.188 \%$ after 14 days at $20^{\circ} \mathrm{C}$. From that point, the growth of the expansion curve levels off. The specimens mixed with $\mathrm{MgO}$ (110 s) were similar to the specimens mixed with $\mathrm{MgO}(65 \mathrm{~s})$. Nevertheless, there was a trend for the specimens mixed with $\mathrm{MgO}(143 \mathrm{~s}$ ) and $\mathrm{MgO}$ (190 s), except rapid growth in the first three days, that the expansion in the early period was not large, and the increase in the later period became larger, especially curing at $38^{\circ} \mathrm{C}$. Under curing at $60^{\circ} \mathrm{C}$ and $80^{\circ} \mathrm{C}$, these samples, with low activity or high activity, reached maximum expansion on about the 28 th day (Figure $5 c, d$ ).

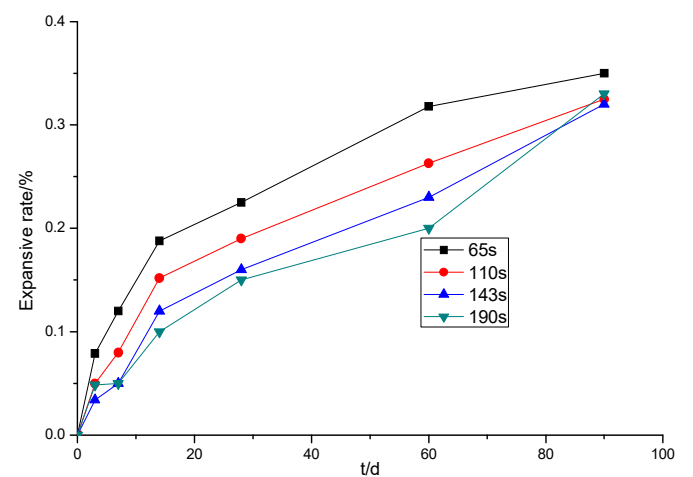

(a)

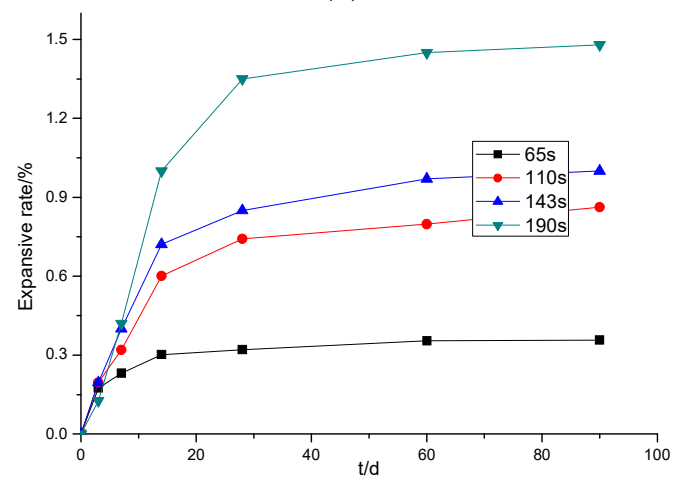

(c)

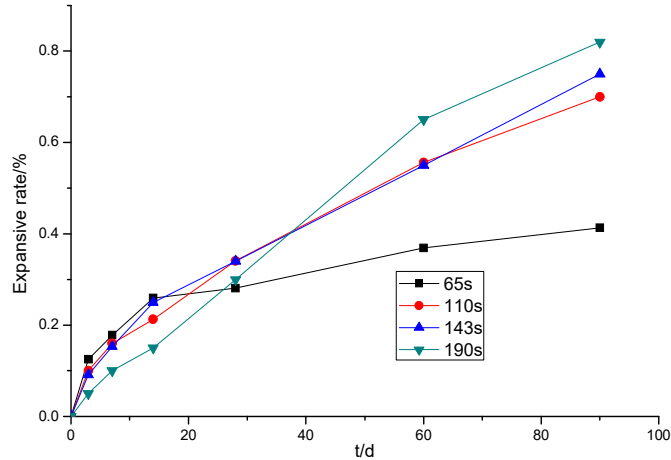

(b)

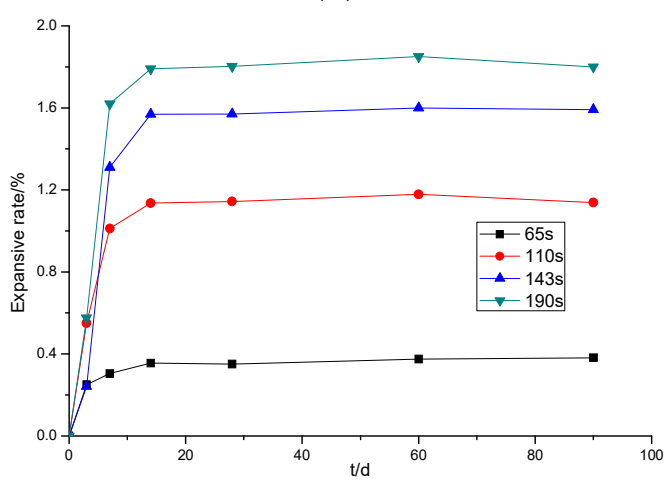

(d)

Figure 5. The expansion curves of cement paste mixed with $\mathrm{MgO}(10 \%)$ of different activities at different temperatures: (a) $20{ }^{\circ} \mathrm{C}$; (b) $38^{\circ} \mathrm{C}$; (c) $60{ }^{\circ} \mathrm{C}$; (d) $80^{\circ} \mathrm{C}$.

Notably, in Figure 5a-d, no matter for the expansion speed rate (the slope of the expansion rate curve) or the expansion rate, specimens mixed with low activity $\mathrm{MgO}$ were initially smaller than specimens mixed with high activity $\mathrm{MgO}$, but the former exceeded the latter as the curing time increases. The difference was that the increase in temperature accelerated these two surpassing times. Generally speaking, specimens mixed with low activity $\mathrm{MgO}$ generated greater expansion.

These demonstrated that at the same curing temperature, the contribution of high activity $\mathrm{MgO}$ to the expansion of cement paste was mainly reflected in the early hydration stage, while the compensated supply of $\mathrm{MgO}$ with low hydration activity to cement paste was mainly reflected in the later period of hydration, which is consistent with Lanqing 
Yu's research [25]. Moreover, the final expansion produced by the cement mixed with low activity $\mathrm{MgO}$ was larger.

\subsection{Measurement of Hydration Degree of Periclase in Cement Paste}

Figures 6 and 7 and Tables 5 and 6 show at different curing temperatures, the XRD patterns, and corresponding hydration degree of cement paste specimens mixed with $10 \%$ $\mathrm{MgO}$ of different activities, including $65 \mathrm{~s}$ and $190 \mathrm{~s}$. Figures 6 and 7 demonstrate that at the same curing temperature, the intensity of the diffraction peaks of periclase was gradually reduced with the increase of the curing age, instead, the intensity of the diffraction peaks of brucite gradually increased. It meant that with the increase in curing age, the content of periclase in cement paste specimens decreased, the amount of brucite increased, and the hydration degree of periclase increased. These results are also reflected in Tables 5 and 6, which additionally reflect that high activity $\mathrm{MgO}(65 \mathrm{~s})$ was mainly hydrated in the early hydration stage, while low activity $\mathrm{MgO}$ (190 s) was mainly hydrated in the later period of hydration. Curing temperature could speed up the whole hydration process. These phenomena coincided with the law of specimen expansion. It should be pointed out that in the later period of hydration, especially under the curing temperature of $38^{\circ} \mathrm{C}, 60^{\circ} \mathrm{C}$, and $80^{\circ} \mathrm{C}$, although the hydration degree of low activity $\mathrm{MgO}$ was always lower than that of high activity $\mathrm{MgO}$, the expansion rate of specimens mixed with low activity $\mathrm{MgO}$ was much higher than that of specimens mixed with high activity $\mathrm{MgO}$. It further explained that the expansion of cement paste mixed with light-burned $\mathrm{MgO}$ was not a simple $\mathrm{MgO}$ hydration process.

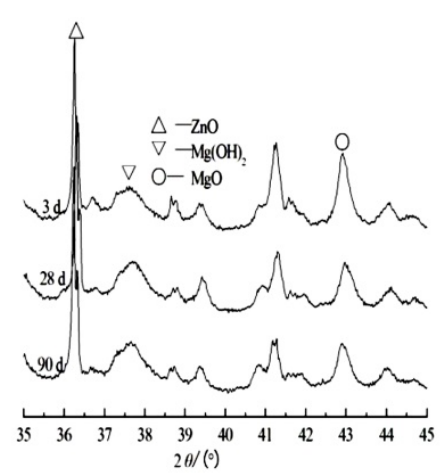

(a)

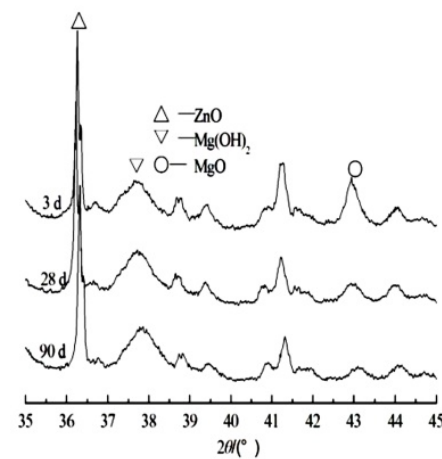

(c)

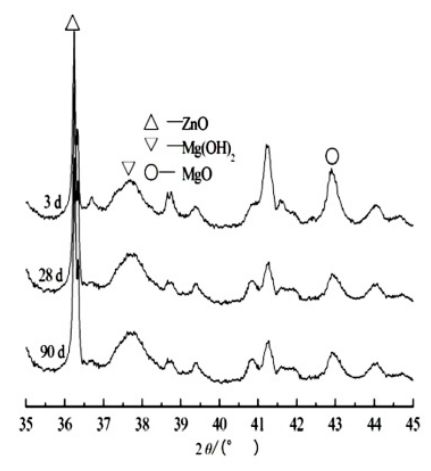

(b)

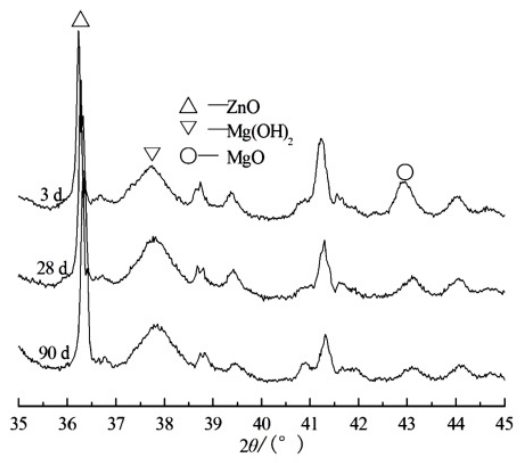

(d)

Figure 6. XRD pattern of hydration slurry mixed with $\mathrm{MgO}(65 \mathrm{~s})$ at different temperatures: (a) $20^{\circ} \mathrm{C}$; (b) $38^{\circ} \mathrm{C}$; (c) $60^{\circ} \mathrm{C}$; (d) $80^{\circ} \mathrm{C}$. 


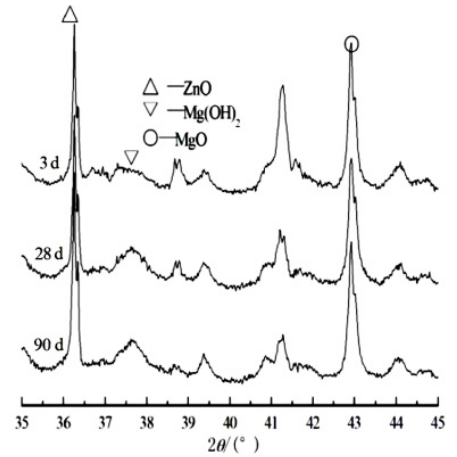

(a)

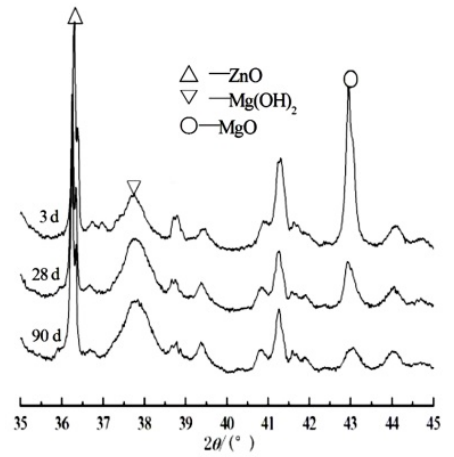

(c)

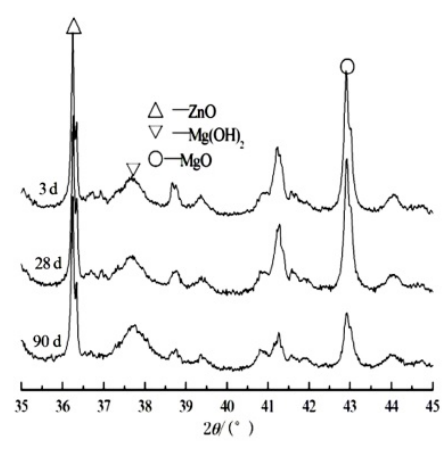

(b)

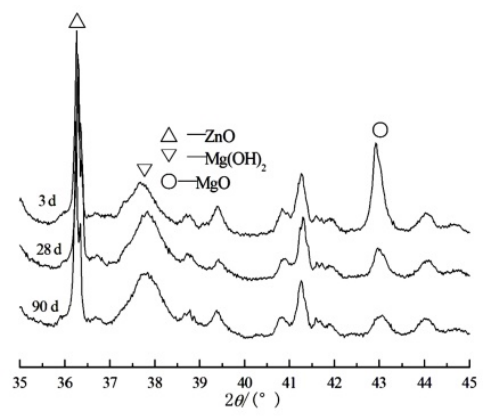

(d)

Figure 7. XRD pattern of hydration slurry mixed with $\mathrm{MgO}(190 \mathrm{~s})$ at different temperatures: (a) $20^{\circ} \mathrm{C}$; (b) $38^{\circ} \mathrm{C}$; (c) $60{ }^{\circ} \mathrm{C}$; (d) $80^{\circ} \mathrm{C}$.

Table 5. The hydration degree of $\mathrm{MgO}$ (65 s) in cement paste.

\begin{tabular}{cccccc}
\hline $\begin{array}{c}\text { Curing } \\
\text { Temperature/ }{ }^{\circ} \mathbf{C}\end{array}$ & $\begin{array}{c}\text { Curing } \\
\text { Age/Day }\end{array}$ & Loss/\% & $\begin{array}{c}\text { Content of } \\
\text { Brucite /\% }\end{array}$ & $\begin{array}{c}\text { Content of } \\
\text { Periclase/\% }\end{array}$ & $\begin{array}{c}\text { Hydration } \\
\text { Degree/\% }\end{array}$ \\
\hline \multirow{2}{*}{20} & 3 & 16.82 & 6.23 & 4.65 & 45.88 \\
& 28 & 23.47 & 6.48 & 3.95 & 50.03 \\
30 & 23.93 & 7.18 & 3.25 & 68.64 \\
\hline \multirow{2}{*}{30} & 3 & 17.93 & 7.16 & 3.76 & 55.64 \\
& 28 & 22.24 & 7.13 & 3.45 & 57.05 \\
38 & 90 & 23.29 & 9.35 & 1.41 & 82.20 \\
\hline \multirow{3}{*}{30} & 3 & 18.91 & 8.50 & 2.51 & 70.01 \\
& 28 & 22.6 & 8.83 & 1.85 & 77.06 \\
& 90 & 24.04 & 9.62 & 0.95 & 87.89 \\
\hline \multirow{2}{*}{80} & 3 & 18.97 & 7.52 & 3.37 & 59.73 \\
& 28 & 21.93 & 9.82 & 1.01 & 90.48 \\
& 90 & 23.97 & 10.52 & 0.38 & 95.16 \\
\hline & 3 & 18.78 & 9.44 & 1.70 & 79.73 \\
& 28 & 20.46 & 10.62 & 0.68 & 91.73 \\
& 90 & 20.37 & 10.77 & 0.34 & 96.27 \\
\hline
\end{tabular}


Table 6. The hydration degree of $\mathrm{MgO}$ (190 s) in cement paste.

\begin{tabular}{cccccc}
\hline $\begin{array}{c}\text { Curing } \\
\text { Temperature/ }{ }^{\circ} \mathbf{C}\end{array}$ & $\begin{array}{c}\text { Curing } \\
\text { Age/Day }\end{array}$ & Loss/\% & $\begin{array}{c}\text { Content of } \\
\text { Brucite /\% }\end{array}$ & $\begin{array}{c}\text { Content of } \\
\text { Periclase/\% }\end{array}$ & $\begin{array}{c}\text { Hydration } \\
\text { Degree/\% }\end{array}$ \\
\hline \multirow{2}{*}{20} & 3 & 18.28 & 4.94 & 5.68 & 30.28 \\
& 28 & 18.30 & 6.68 & 4.16 & 32.59 \\
30 & 23.23 & 6.38 & 4.06 & 58.92 \\
\hline \multirow{2}{*}{30} & 3 & 14.36 & 5.59 & 5.34 & 41.94 \\
& 28 & 20.50 & 6.04 & 4.57 & 46.47 \\
38 & 90 & 22.15 & 7.47 & 3.14 & 65.24 \\
\hline \multirow{3}{*}{30} & 3 & 14.07 & 6.61 & 4.95 & 43.34 \\
& 28 & 16.52 & 6.67 & 4.29 & 48.15 \\
& 90 & 23.59 & 8.48 & 2.07 & 71.77 \\
\hline \multirow{2}{*}{80} & 3 & 16.85 & 6.44 & 4.47 & 47.06 \\
& 28 & 17.01 & 11.39 & 0.19 & 83.92 \\
& 90 & 23.18 & 9.93 & 0.76 & 87.78 \\
\hline & 3 & 14.30 & 11.42 & 0.48 & 84.78 \\
& 28 & 14.49 & 11.43 & 0.45 & 85.10 \\
\hline
\end{tabular}

In a word, the increase of temperature and hydration age can improve the hydration degree of periclase. The increase of temperature can promote the compensation of magnesia to cement-based materials in a short time. For cement-based materials with early shrinkage, $\mathrm{MgO}$ expansion agents with relatively high hydration activity should be used. On the contrary, for cement-based materials with relatively obvious late shrinkage, $\mathrm{MgO}$ expansion agents with lower hydration activity were more suitable. Furthermore, the expansion of cement paste mixed with light-burned $\mathrm{MgO}$ was not a simple $\mathrm{MgO}$ hydration process.

\subsection{Microstructure of Specimens}

Figure $8 \mathrm{a}, \mathrm{b}$ are SEM images of $\mathrm{MgO}$ of hydration activity $65 \mathrm{~s}$ and SEM images of $\mathrm{Mg}(\mathrm{OH})_{2}$ after hydration. It is easy to see from the figure that magnesium oxide was clustered together, and these single particles were made up of a large number of magnesium oxide crystallites. After $\mathrm{MgO}$ hydrated into $\mathrm{Mg}(\mathrm{OH})_{2}$, short pieces appeared, and the phenomenon of superimposed flakes was observed.

In Figure $8 \mathrm{c}, \mathrm{e}-\mathrm{g}$, it can be seen that with the growth of hydration age, $\mathrm{MgO}$ gradually hydrated to $\mathrm{Mg}(\mathrm{OH})_{2}$, diffusing and growing into the surrounding pores in a dispersed state. From Figure $8 \mathrm{f}$, it was distinct that there were a small amount of clear flakes of $\mathrm{Mg}(\mathrm{OH})_{2}$ crystals at 28 days, while a large number of flaky $\mathrm{Mg}(\mathrm{OH})_{2}$ crystals appeared under $90 \mathrm{~d}$ curing (Figure $8 \mathrm{~g}$ ). 


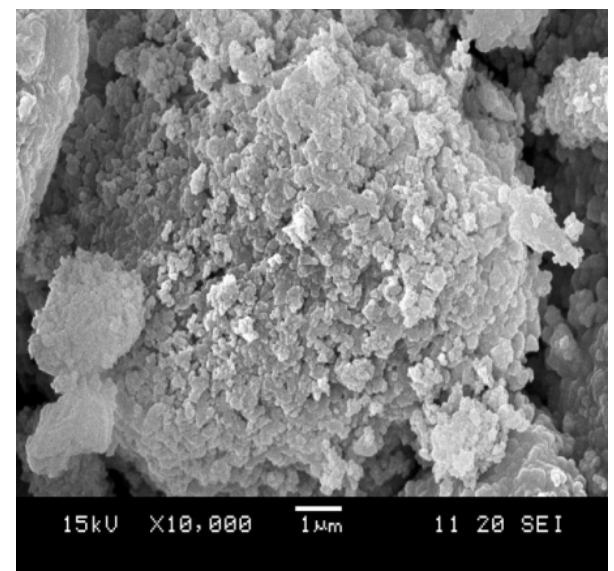

(a)

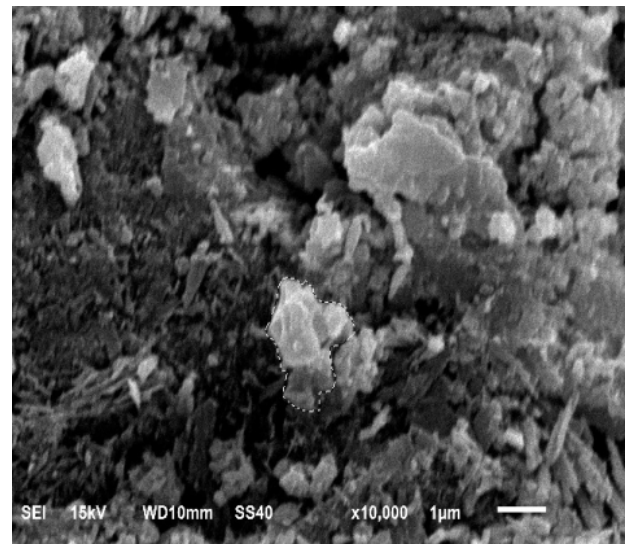

(c)

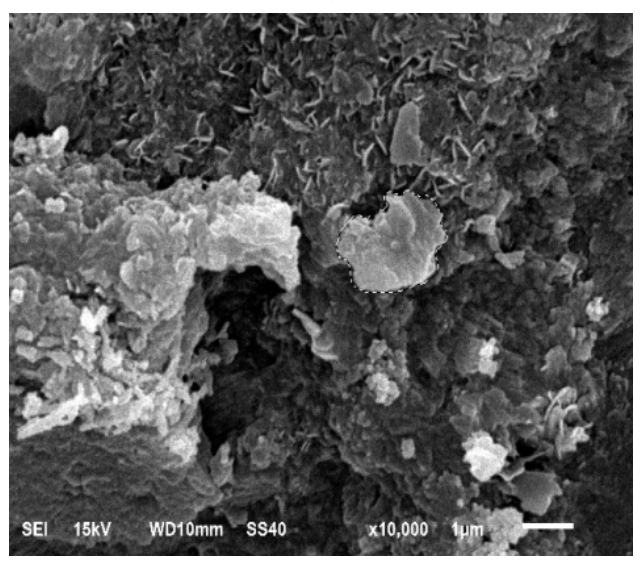

(e)

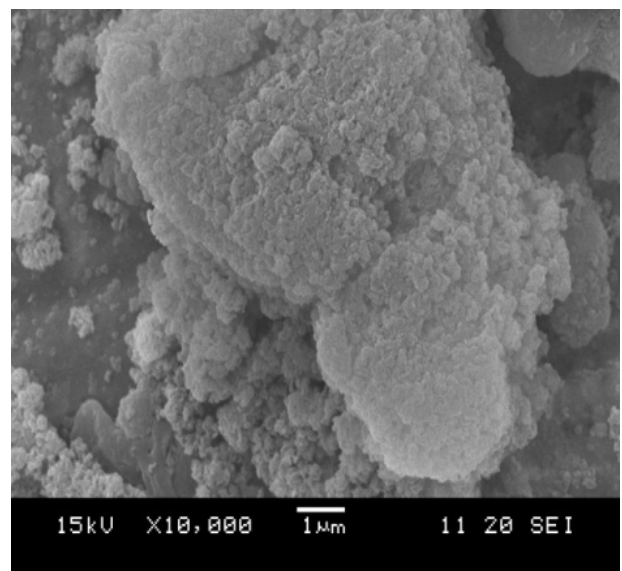

(b)

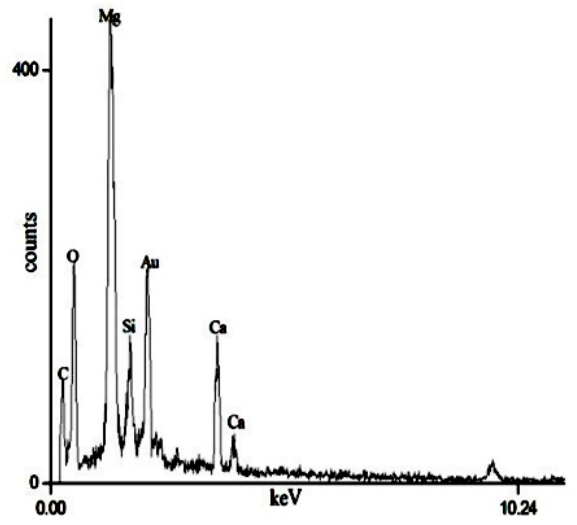

(d)

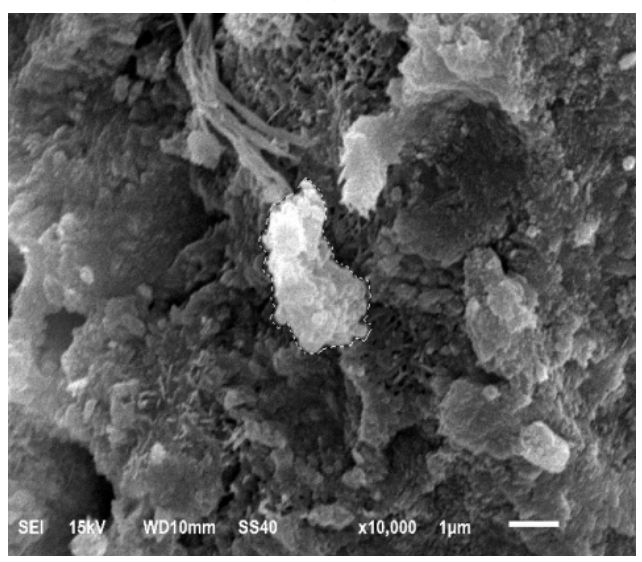

(f)

Figure 8. Cont. 


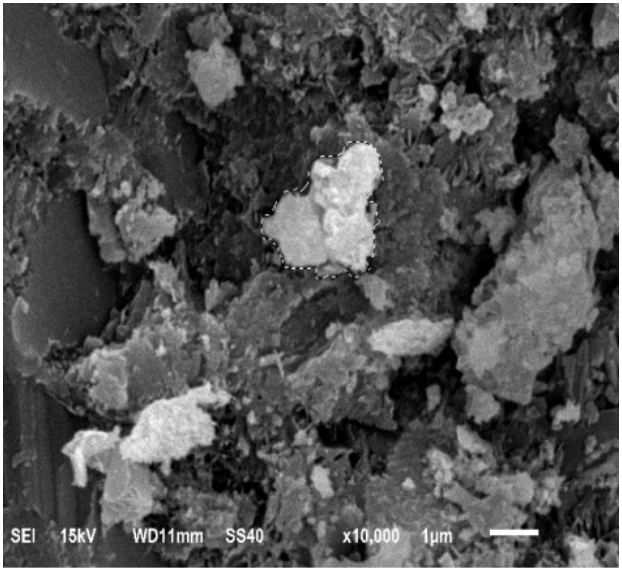

(g)

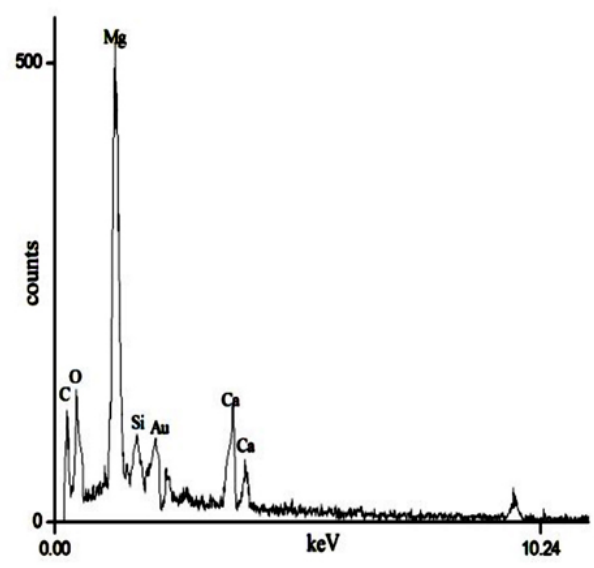

(h)

Figure 8. SEM images of cement paste mixed with $\mathrm{MgO}(65 \mathrm{~s})$ at $20^{\circ} \mathrm{C}$ : (a) $\mathrm{MgO}, \mathrm{SEM}$; (b) $\mathrm{Mg}(\mathrm{OH}) 2, \mathrm{SEM}$; (c) 3d, SEM; (d) 3d, EDS; (e) 7d, SEM; (f) 28d, SEM; (g) 90d, SEM; (h) 90d, EDS.

\subsection{Discussion According to the Aforementioned Results}

There are three possible reasons for the different expansion phenomena between the high activity and the low activity $\mathrm{MgO}$ : Firstly, the hydration reaction activity was different. Due to the high hydration rate of high activity $\mathrm{MgO}$, a large amount of $\mathrm{Mg}(\mathrm{OH})_{2}$ can be produced in the early stage of hydration, resulting in rapid expansion in the early stage. Therefore, the amount of $\mathrm{MgO}$ supplied in the late hydration was relatively small, and the resulting expansion was also small. Instead, there were more expansion components for the relatively low activity $\mathrm{MgO}$ in the late hydration stage. Secondly, the internal structure was different. The hydration of $\mathrm{MgO}$ occurred at the grain surface, internal pores [16], and $\mathrm{MgO}$ grain boundaries [3] at the same time. On the one hand, the high activity $\mathrm{MgO}$ was porous and had a large specific surface area, which provided a certain growing space for the hydration products on the inner pore surface [16]. Hence, the effective expansion of these hydration was small. On the other hand, the atom order at the grain boundary with many defects was irregular, so the atoms here easily reacted with water [29]. Moreover, there was little room left for growth of the hydration product at the grain boundary, resulting in greater expansion here. For high activity $\mathrm{MgO}$ (Figure 9), due to the fact that the internal surface area was much larger than the grain boundary area [28], the hydration of internal surface area played a major role. For low activity $\mathrm{MgO}$ (Figure 10), contrary to the former, more hydration products were formed at grain boundaries [28], while the growth space at grain boundaries was smaller. Therefore, high activity $\mathrm{MgO}$ produced less effective expansion than low activity $\mathrm{MgO}$. Thirdly, the change in properties of cement product matrix was also a considerable reason. Cement paste had viscoelasticity [32] and this viscoelasticity was time-efficient [33]. The cement paste generated viscous flow under the expansion force generated by the hydration of $\mathrm{MgO}$, thereby absorbing part of the expansion energy, and the viscous flow had a relaxing effect on the expansion force, ultimately reducing the expansion [32]. The hydration of high activity $\mathrm{MgO}$ occurred mainly in early stages when the viscosity of cement paste is small and easy to produce viscous flow [33]. Therefore, a large amount of expansion energy was consumed in viscous flow, leading to less expansion [29]. However, for the low activity $\mathrm{MgO}$, hydration was concentrated in the late period when the viscous flow was slow, consuming less energy of expansion, finally resulting in more expansion than the former. 

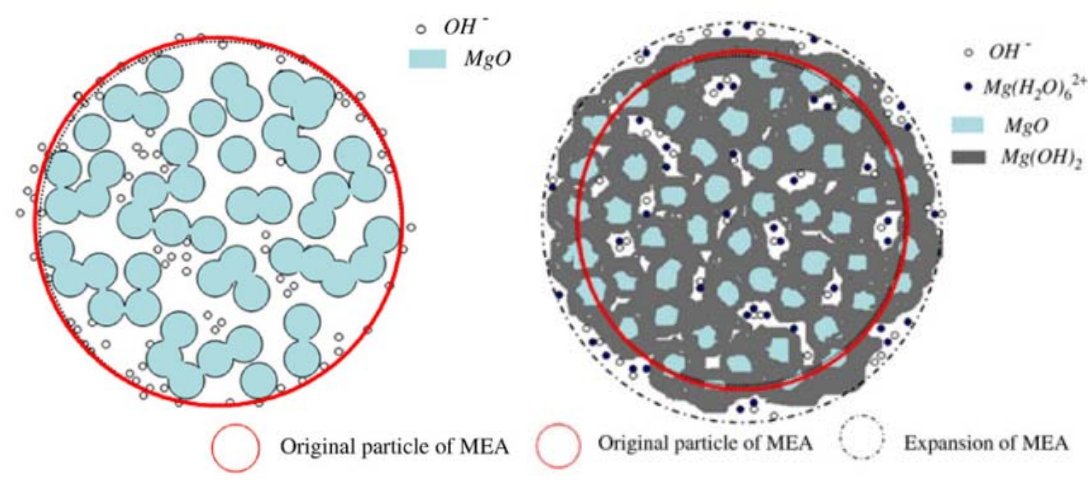

Figure 9. Hydration and expansion model of the porous MEA with high activity in the cement paste. Reprinted with permission from Professor Mo Liwu, Copyright 2009 Elsevier Ltd. [34].
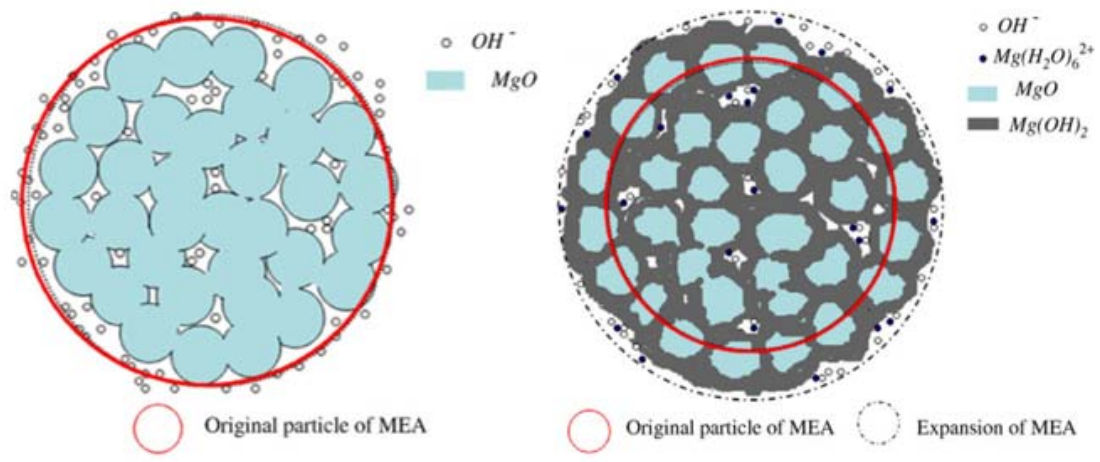

Figure 10. Hydration and expansion model of the MEA with less pores and with low activity in the cement paste Reprinted with permission from Professor Mo Liwu, Copyright 2009 Elsevier Ltd. [34].

\section{Conclusions}

In this study, the expansion behavior and hydration degree of cement paste mixed with light-burned $\mathrm{MgO}$ were mainly discussed, providing some guidance in designing new cement systems later. The conclusions can be shown as follows.

(1) At the same temperature, the hydration of high activity $\mathrm{MgO}$ and the expansion behavior occurred mainly in the early stage of hydration, while the hydration of low activity $\mathrm{MgO}$ and the expansion behavior had a high contribution rate in the later stage of hydration. Through hydration model analysis, the reasons found for the differences included three aspects: different hydration reaction activities, distinct internal structure of mixed $\mathrm{MgO}$, and the change in properties of cement product matrix.

For cement-based materials with early shrinkage, $\mathrm{MgO}$ expansion agents with relatively high hydration activity should be used. On the contrary, for cement-based materials with relatively obvious late shrinkage, $\mathrm{MgO}$ expansion agents with lower hydration activity were more suitable.

(2) The curing temperature greatly influences the hydration speed of $\mathrm{MgO}$. When the other conditions are the same, the higher the curing temperature, the greater the hydration degree of $\mathrm{MgO}$, the greater the expansion rate, the faster the expansion of cement mixed with light-burned $\mathrm{MgO}$.

(3) The increase of $\mathrm{MgO}$ content can promote the expansion of cement. The greater the dosage, the greater the expansion rate and the faster the expansion rate, especially when the dosage is more than $3.6 \%$, the growing rate of expansion curve (expansion speed rate) enhanced. Moreover, the content of $\mathrm{MgO}$ did not have a linear relationship with its corresponding expansion rate.

(4) The addition of $\mathrm{MgO}$ had little effect on the strength of cement paste, only a small reduction, as it counteracted the content of the other components which can provide strength. 
Author Contributions: Conceptualization, L.X.; tests and data interpretation, Y.W. and C.Z.; writingoriginal draft preparation, Y.W.; review and editing, Y.W. and L.X. All authors have read and agreed to the published version of the manuscript.

Funding: This research was financially supported by the National Key Research and Development Plan of China (2016YFB0303601-2), and the Priority Academic Program Development of Jiangsu Higher Education Institutions (PAPD).

Data Availability Statement: The data supporting the findings of this paper are available from the corresponding authors upon reasonable request.

Acknowledgments: The authors would like to acknowledge the assistance from Tao Feng, Ruijie Jiang, Xin Shi, Nan Wu and Jian Han from Nanjing Tech University.

Conflicts of Interest: The authors declare no conflict of interest.

\section{References}

1. Lea, F.M. The Chemistry of Cement and Concrete; Chemical Publishing Company: New York, NY, USA, 1971.

2. Mehta, P. History and Status of Performance Tests for Evaluation of Soundness of Cements; ASTM International: West Conshohocken, PA, USA, 1978.

3. Mo, L.W. Microstructure and Property of MgO-Type Expansive Agent. Ph.D. Thesis, Nanjing Tech University, Nanjing, China, 2008.

4. Mehta, P.; Pirtz, D. Magnesium oxide additive for producing selfstress in mass concrete. In Proceedings of the 7th International Congress on the Chemistry of Cement, Paris, France, 30 June-4 July 1980.

5. Li, C. Review of quick damming technology of MgO concrete. Adv. Sci. Technol. Water Resour. 2013, 33, 82-87. [CrossRef]

6. Gao, P.W.; Wu, S.X.; Lu, X.L.; Deng, M.; Lin, P.H.; Wu, Z.R.; Tang, M.S. Soundness evaluation of concrete with MgO. Constr. Build. Mater. 2007, 21, 132-138. [CrossRef]

7. Zhu, B. On construction of dams by concrete with gentle volume expansion. J. Hydroelectr. Eng. 2000, 1-13. [CrossRef]

8. Ye, Q.; Chen, H.X.; Wang, Y.Q. Effect of $\mathrm{MgO}$ and gypsum content on long-term expansion of low heat Portland slag cement with slight expansion. Cem. Concr. Compos. 2004, 26, 331-337. [CrossRef]

9. Gao, P.; Lu, X.; Geng, F.; Li, X.; Hou, J.; Lin, H.; Shi, N. Production of MgO-type expansive agent in dam concrete by use of industrial by-products. Build. Environ. 2008, 43, 453-457. [CrossRef]

10. Xu, L.L.; Deng, M. Dolomite used as raw material to produce MgO-based expansive agent. Cem. Concr. Res. 2005, 35, 1480-1485. [CrossRef]

11. Xu, L.L.; Deng, M.; Wang, X.; Zhao, X. Studies on preparation of a new expansive agent based on MgO. J. Mater. Sci. Eng. 2004, 22, 249-253. [CrossRef]

12. Xu, L.L.; Deng, M.; Zhao, X. Compensating shrinkage of cement paste by new MgO-based expansive material. J. Build. Mater. 2005, 8, 67-70. [CrossRef]

13. Zhao, X.; Deng, M. Preparation and Performance of MgO-type Expansive Agent. J. East China Inst. Technol. 2005, 28, 71-75. [CrossRef]

14. Cao, F.; Liu, Y.; Yan, P. Properties and mechanism of the compound MgO expansive agent (CMEA) produced by calcining the mixture of dolomite and serpentine tailings. Constr. Build. Mater. 2021, 277, 122331. [CrossRef]

15. Liu, P.C.; Deng, M. Regulating the Expansion Characteristics of Cementitious Materials Using Blended MgO-Type Expansive Agent. Materials 2019, 12, 976. [CrossRef] [PubMed]

16. Liu, P.; Kendelewicz, T.; Brown, G.E.; Parks, G.A. Reaction of water with MgO (100) surfaces. Part I: Synchrotron X-ray photoemission studies of low-defect surfaces. Surf. Sci. 1998, 412, 287-314. [CrossRef]

17. Liu, P.; Kendelewicz, T.; Brown, G.E.; Parks, G.A. Reaction of water with MgO (100) surfaces. Part II: Synchrotron photoemission studies of defective surfaces. Surf. Sci. 1998, 412, 315-332. [CrossRef]

18. Mejias, J.A.; Berry, A.J.; Refson, K.; Fraser, D.G. The kinetics and mechanism of MgO dissolution. Chem. Phys. Lett. 1999, 314, 558-563. [CrossRef]

19. Xu, Y.M.; Xu, L.L.; Li, W.W. Research Progress of the Periclase and Quantitative Method in Cement Clinker. Mater. Rep. 2013, 27, 355-358.

20. Cao, F.; Miao, M.; Yan, P. Effects of reactivity of MgO expansive agent on its performance in cement-based materials and an improvement of the evaluating method of MEA reactivity. Constr. Build. Mater. 2018, 187, 257-266. [CrossRef]

21. Zheng, H.W. Magnesium Oxide in Cement. Fujian Build. Mater. 2000, 3, 9-11.

22. Qian, H.Y.; Li, S.Y.; Deng, M. Hydrochemical Kinetics of Light-Burned Magnesia. Ind. Miner. Process. 2007, 12, 1-4.

23. Liu, J.P.; Wang, Y.J.; Tian, Q.; Zhang, S.Z. Temperature sensitivity of light calcined magnesia expansion agent and its mechanism analysis. J. Southeast Univ. 2011, 41, 359-364.

24. Yu, L.Q.; Deng, M.; Mo, L.W. Effects of Lightly Burnt MgO Expansive Agent on the Deformation and Microstructure of Reinforced Concrete Wall. Adv. Mater. Sci. Eng. 2019, 4, 1948123. [CrossRef] 
25. Tian, Q.; Tu, Y.J.; Liu, J.P.; Miao, C.W. Temperature Sensitivity Analysis on Expansive Property of MgO Composite Expansion Agent. Water Power 2010, 36, 49-51, 86. [CrossRef]

26. Ye, Q.; Yu, K.; Zhang, Z. Expansion of ordinary Portland cement paste varied with nano-MgO. Constr. Build. Mater. 2015, 78, 189-193. [CrossRef]

27. Chatterji, S. Mechanism of expansion of concrete due to the presence of dead-burnt $\mathrm{CaO}$ and MgO. Cem. Concr. Res. 1995, 25, 51-56. [CrossRef]

28. Kitamura, A.; Oniduka, K.; Tanaka, K. Hydration characteristics of magnesia. Taikabutsu Overseas 1996, 16, 3-11.

29. Cao, F.; Yan, P. The influence of the hydration procedure of $\mathrm{MgO}$ expansive agent on the expansive behavior of shrinkagecompensating mortar. Constr. Build. Mater. 2019, 202, 162-168. [CrossRef]

30. Cao, F.; Miao, M.; Yan, P. Hydration characteristics and expansive mechanism of MgO expansive agents. Constr. Build. Mater. 2018, 183, 234-242. [CrossRef]

31. Salomao, R.; Bittencourt, L.; Pandolfelli, V. A novel approach for magnesia hydration assessment in refractory castables. Ceram. Int. 2007, 33, 803-810. [CrossRef]

32. Jennings, H.M.; Bullard, J.W.; Thomas, J.J.; Andrade, J.E.; Chen, J.J.; Scherer, G.W. Characterization and modeling of pores and surfaces in cement paste. J. Adv. Concr. Technol. 2008, 6, 5-29. [CrossRef]

33. Thomas, J.J.; Jennings, H.M. A colloidal interpretation of chemical aging of the C-S-H gel and its effects on the properties of cement paste. Cem. Concr. Res. 2006, 36, 30-38. [CrossRef]

34. Mo, L.W.; Deng, M.; Tang, M.S. Effects of calcination condition on expansion property of MgO-type expansive agent used in cement-based materials. Cem. Concr. Res. 2010, 40, 437-446. [CrossRef] 